\title{
A Comparative Analysis of the Safety Awareness of Korean and Chinese Construction Workers
}

\author{
Zhang, Zhen An, Sung-Hoon* \\ Department of Architectural Engineering, Daegu University, Gyeongsan-Si, Gyeongsangbuk-Do, 706-140, Korea
}

\section{Abstract}

Accompanied by Chinese strong economic growth rates and development of demand for the construction industry, Chinese construction industry has already become one of the largest construction markets in the world. Unfortunately, the frequent occurrence of safety incidents on Chinese construction sites is a large obstacle for other countries construction companies seeking to enter the Chinese construction market. This study aims to analyze and compare the safety awareness of Chinese and Korean construction workers. Our research showed that the safety awareness of Korean construction workers is far higher than that of their Chinese counterparts, particularly in terms of the efficiency of safety education and the observance of safety rules. The development of a safety management plan based on these results will contribute to reducing the frequency of accidents on Chinese construction sites.

Keywords : safety management, construction accidents, safety awareness, chinese construction industry

\section{Introduction}

\subsection{Research background and objective}

China have grown at staggering pace into economic juggernauts. When China joined the World Trade Organization, this pace became more faster. The total production cost in the construction industry in China has been increasing annually, and it has become one of China' s significant backbone industries for economic growth. In fact, China already has the largest construction market in the world[1]. For this reason, Korean construction companies are striving to make inroads into the construction market in China.

As the size of China's construction market grows, an increasing number of safety incidents at

\section{Received : March 20, 2012}

Revision received : June 8, 2012

Accepted : July 2, 2012

* Corresponding author: An, Sung-Hoon

[Tel: 82-53-850-6518, E-mail: shan@daegu.ac.kr]

(c) 2012 The Korea Institute of Building Construction, All rights reserved. construction sites in China have been reported, leading to a stronger interest in safety management on construction sites. Since the enactment of the People' s Republic of China Labor Contract Law in 1994 and the People' S Republic of China Construction Law in 1998, there have been some improvements in construction safety. In addition, the State Council of the People' s Republic of China issued safety management regulations for building construction in 2003, enacting the related legal criteria.

However, despite such efforts, the frequency of safety incidents over the last 5 years has still been high, and almost 1,000 construction workers annually lose their lives due to safety incidents [2]. The frequency with which construction safety incidents occur in China is a barrier preventing foreign construction companies from making inroads into China, and is ultimately an obstacle to the liberalization and globalization of the Chinese construction market. Thus, the problem is 
recognized as one of the obstacles that must be overcome for Korean construction companies to enter the Chinese construction market.

Although there may be various methods that can be used to reduce safety incidents, changing the safety awareness level of construction workers is certainly a significant method[3]. Therefore, this study aims to perform a comparative analysis of the safety awareness of Korean and Chinese construction workers to help Korean construction companies carry out effective safety management in construction sites in China.

\subsection{Research Scope and Method}

The research scope is limited to a comparative analysis of the safety awareness of Korean and Chinese construction workers.

This study compare the safety awareness of Korean and Chinese construction workers, the literature was first reviewed to understand the factors influencing safety awareness. Then, the current status of the safety awareness of Korean and Chinese construction workers was researched, and a survey of Korean and Chinese workers was conducted to perform a comparative analysis.

For this study, a survey was performed of laborers (unskilled workers) working at construction sites in Korea and in China. Data was collected from January 2011 to April 2011. A total of 220 questionnaires were used as effective data, though some questionnaires were excluded for having some answers missed or for the replies being insufficient. Of 220 questionnaires, 120 questionnaires of this survey were collected from Korean laborers working at 6 small construction sites and 100 questionnaires from Chinese laborers working at 5 small construction sites. The data collected was analyzed using SPSS, a statistical software package.

\section{Review of previous studies on safety awareness of construction workers}

Many studies have been done on safety awareness, as it is considered a key factor in preventing safety incidents in building construction. Studies on the safety awareness of construction workers can be divided into two categories: studies on the general current state of safety awareness and studies on the factors influencing safety awareness.

Regarding the studies on the general current state of safety awareness, Lee[4] found that construction workers considered their safety important, and reckless construction and a lack of work experience among new construction workers had a direct influence on the occurrence of safety incidents. Lee[5] revealed that while most construction workers considered protective gear as mandatory to wear, the number of workers who actually wore the protective gear was rather small, and so was the number of workers who participated in safety education. Kim[6] found that both construction workers and managers thought of safety management as an obstruction to the working process, and while construction workers wanted safety facilities installed or sought improvements in the working environment, the managers said that the installation of a safety facility would increase construction cost, and safety facilities were only installed as required. Lee[7] discovered that construction workers considered protective gear to be necessary, but many did not wear it out of discomfort. Workers pointed out violations of safety rules as the main cause of safety incidents.

Regarding studies on the factors influencing safety awareness, Jeon[8] reported that industrial safety awareness of construction workers had 
nothing to do with practical experience of an industrial disaster, but had something to do with immersion of duty. Kim[9] indicated that safety awareness of construction workers was shown to be comparatively high, and found a relatively high correlation between safety on the construction site and safety awareness of workers. Lee[3] pointed out that participation in safety education, observation of safety rules and appropriateness of safety education content could affect improvements in the safety awareness of the workers. Cho[10] researched safety awareness and safety training of construction workers, and found that workers with more than 3 years of experience showed lower safety awareness, and that it would be effective to provide safety training for the workers every 3 years. Lee[11] presented an improvement plan for safety management based on an analysis of the safety awareness of construction workers, indicating that the workers who had experienced an industrial disaster had a slightly higher safety awareness. Kim[12] studied the relationship between worker personality and safety awareness, and found that frequency of direct and indirect experience of an industrial disaster, educational background, and average working hours per day affected the safety awareness of construction workers.

Our review of the previous studies found that many studies have been conducted on safety awareness of construction workers, but there have been no studies that have done a comparative analysis of the safety awareness of construction workers in different countries.

\section{Comparison of the safety awareness of Korean and Chinese construction workers}

\subsection{Factors influencing safety awareness of construction workers}

This study is a comparative analysis of the safety awareness of Korean and Chinese construction workers. First, factors to measure safety awareness of construction workers should be selected. To do this, safety awareness factors of construction workers were enumerated based on the previous studies[3,8,9,10,11,12], and then four factors were finally selected based on the advice of a construction site manager(expert). The four factors are riskprocessing system, safety education efficiency, safety intelligibility and safety rules observation.

The risk-processing system refers to how a worker responds when he encounters a danger. Here, workers fall into two categories: those who continue to work without reporting the danger, despite being aware of it, and those who take the necessary steps before continuing to work. When a worker takes the necessary steps before continuing to work, it can reduce the safety incidents.

Safety education efficiency refers to how effectively the responsible construction company or site manager provides safety training to workers. Construction sites (managers) can be divided into two categories: those who provide thorough safety training and give caution to the workers and those who provide safety training as a formality. Safety training can be the most important step to prevent safety incidents at a job site.

Safety intelligibility refers to how well the workers understand the safety procedures. As an individual construction worker's caution and effort can be the most important factor for his own safety, when the worker has a high understanding of safety, he will be cautious to ensure safety and avoid any potential danger, leading to a reduction in safety incidents.

Safety rules observation refers to how appropriately the construction company or manager disciplines the offender when a worker violates any safety 
rule. When safety rules are applied to the site strictly, workers are more aware of safety when they work, which can affect the frequency of safety disasters.

\subsection{Survey}

A survey of Korean and Chinese construction workers was conducted to perform a comparative analysis of their safety awareness. Data collected was analyzed using SPSS, a statistical software package.

When the questionnaire was drawn up, the questions on the four factors that can measure safety awareness of the workers (safetyprocessing system, safety training efficiency, safety intelligibility, safety rules observation) were used, as in the previous studies. If there were some differences in nuance, though the meaning was the same, some adjustment was done[3,8,9,10,11,12]. In addition, to understand the safety awareness based on individual attributes, six attributes were selected based on the previous studies[13]. The six attributes are gender, age, educational background, continuous service years, work type, and average working hours per day.

In this study, to understand the relationship between safety awareness of construction workers and industrial disasters, the workers were surveyed regarding their experience of any industrial disaster. In the preliminary research for the workers, there were no workers who had experienced a serious injury, but some that had experienced a slight injury, and many that had frequent experiences of near misses (a narrow escape from an accident). Therefore, workers were surveyed on how many near misses they had per month and how many times they had experienced an industrial disaster.

The questionnaire was made by classifying the categories into safety-processing system, safety training efficiency, safety intelligibility and safety rules observation.

In the safety-processing system category, the questions included "When you are aware of a danger, do you report it to the manager after taking the necessary steps?"; "Have you ever made a suggestion to the manager or person in charge?"; "When you are aware of a danger, do you stop the work, report it to the manager and wait until it is dealt with?"; and "When you are aware of a danger, do you continue to work without reporting it to the manager because it can obstruct the working process?"

In the safety training efficiency category, the questions included "Do you think the content of the current safety training is appropriate?"; "Do you actively participate in safety training at the site?"; "Do you think the safety training is done as a formality and is a waste of time?"; "Do you think the safety training is helpful to improve safety conditions for your work?"; and "Do you think the safety training currently done at the site is necessary?"

In the safety intelligibility category, the questions included "Do you think protective gear should be worn at the construction site?"; "Do you think safety incidents occur due to bad luck?"; "Do you take a lot of caution for your own safety during your work?"; "Are you afraid a safety incident might happen to you?"; and "Do you check for any danger before you work?"

In the safety rules observation category, the questions included "Is there any safety manager at the site?"; "Do you think the safety manger actively carries out his duties?"; "Is your construction site operating under safety regulations?"; "Do you think completing the construction work on schedule comes before safety?"; "Do you observe safety rules 
strictly?"; "Do you think safety inspection is done thoroughly?"; "If a worker violates any safety rules, is a punishment given?"; and "Do you think the safety rules are applied strictly?"

\subsection{Reliability analysis of variables}

Several questions were developed to measure one factor influencing safety awareness. For this reason, a reliability analysis was implemented to measure the cohesiveness of the questions for each factor. The Chronbach' s Alpha was used for the reliability analysis. If the Alpha value is higher than 0.6 , it is generally considered reliable[14]. As shown in Table 1, the reliability analysis was conducted for each question by influencing factor, and the questions that were shown to have an Alpha value of less than 0.6 were excluded. Three questions in the safety training category were excluded from the questionnaire.

Table 1. Result of reliability analysis

\begin{tabular}{cccc}
\hline Type & $\begin{array}{c}\text { Original } \\
\text { questions }\end{array}$ & $\begin{array}{c}\text { Final } \\
\text { questions }\end{array}$ & $\begin{array}{c}\text { Chronbach's } \\
\text { Alpha }\end{array}$ \\
\hline $\begin{array}{c}\text { Risk-Processing } \\
\text { system }\end{array}$ & 4 & 4 & 0.61 \\
$\begin{array}{c}\text { Safety education } \\
\text { efficiency }\end{array}$ & 6 & 3 & 0.66 \\
$\begin{array}{c}\text { Safety } \\
\text { Intelligibility }\end{array}$ & 5 & 5 & 0.71 \\
$\begin{array}{c}\text { Safety rules } \\
\text { observance }\end{array}$ & 7 & 7 & 0.77 \\
\hline
\end{tabular}

\subsection{Validity verification}

To evaluate one influencing factor, this questionnaire consists of several questions. Therefore, the questions should be evaluated to reflect the concept the researcher intended to measure, and the validity of how exactly the concept was measured should also be verified. For example, to measure the risk-processing system, four questions were drawn and surveyed. A statistical analysis was done to verify the validity in order to have common factors in the four questions to explain the risk-processing system.

Table 2. Result of factor analysis

\begin{tabular}{ccccc}
\hline \multirow{2}{*}{ Type } & \multicolumn{4}{c}{ Factors } \\
\cline { 2 - 5 } & 1 & 2 & 3 & 4 \\
\hline \multirow{4}{*}{ Safety rules } & .721 & .043 & .147 & -.052 \\
observance & .664 & .199 & -.032 & -.057 \\
& .659 & .119 & .262 & .075 \\
& .605 & .072 & .363 & .059 \\
Risk & .525 & .345 & .025 & -.243 \\
Processing & .223 & .356 & .319 & .129 \\
system & .140 & .726 & -.046 & -.012 \\
& .235 & .599 & .203 & .060 \\
& .403 & .559 & .393 & .063 \\
Safety & .418 & .445 & .125 & -.317 \\
Intelligibility & .247 & -.089 & .759 & .109 \\
& .276 & .219 & .731 & .102 \\
& -.073 & .369 & .502 & .018 \\
Safety & .106 & .394 & .582 & .004 \\
education & -.236 & .045 & .231 & -.251 \\
efficiency & .146 & .037 & -.308 & .767 \\
\hline
\end{tabular}

A factor analysis was conducted to verify the validity for this study. The factor analysis is a method used to reduce or simplify the variables by grouping similar factors to minimize the loss of information. As the factor analysis method, principle factor analysis was used, which is the method in widest use. The criteria to extract the factors was set to be higher than 1 as the eigenvalue. In addition, the Verimax rotating method rotating method was selected as the rotation method [14].

Table 3 is the T-test result to verify the validity of the four factors influencing safety awareness and four new factors were created as indicated. Factor loading was checked for each item by newly created factor. Through this (Table 2), it was verified that the question items well reflected the 
influencing factors, and the validity of the evaluation was also shown to be feasible.

Table 3. Result of T-test for safety awareness

\begin{tabular}{cccccccc}
\hline \multirow{2}{*}{ Type } & \multicolumn{2}{c}{ Korean } & \multicolumn{3}{c}{ Chinese } & T-value & S.p \\
\cline { 2 - 5 } & Mean & S.d & Mean & S.d & & \\
\hline $\begin{array}{c}\text { Risk } \\
\text { Processing } \\
\text { system }\end{array}$ & 19.64 & .483 & 16.92 & .572 & -.082 & .935 \\
$\begin{array}{c}\text { Safety } \\
\text { education } \\
\text { efficiency } \\
\quad \text { Safety }\end{array}$ & 13.99 & .098 & 11.69 & .276 & 4.430 & .000 \\
$\begin{array}{c}\text { Intelligibility } \\
\text { Safety rules } \\
\text { observance }\end{array}$ & 20.94 & 1.42 & 19.70 & 1.41 & .958 & .339 \\
\hline
\end{tabular}

\subsection{Comparison of safety awareness of Korean and} Chinese construction workers

T-test was performed to compare the safety awareness of Korean and Chinese construction workers. The average was calculated and compared by adding each question item by factor to verify the null hypothesis that there is no difference in the safety awareness of Korean and Chinese construction workers.

As indicated in Table 3, the safety awareness of Korean construction workers was slightly higher overall than that of Chinese construction workers, to a level that was statistically significant ( $p<.05)$. By factor, the risk-processing system and safety intelligibility were not significantly different between the two groups. The safety training efficiency was shown to be higher in Korean workers, at 13.99 on average than in Chinese workers at 11.69 on average, which was statistically significant. $(p<.001)$. The safety rules observation was also shown to be higher in Korean workers at 30.38 on average than in Chinese workers at 26.93 on average, which was statistically significant $(\mathrm{p}<001)$.

These differences in safety training efficiency and safety rules observation were considered to be due to the lack of responsibility of the site safety manager in China, the low cultural level of the Chinese workers as former farmers from rural areas, and a lack of precautions or full awareness of current safety training.

Table 4. T-test of experience of disaster

\begin{tabular}{ccccccc}
\hline \multirow{2}{*}{ Type } & \multicolumn{2}{c}{ Korean } & \multicolumn{2}{c}{ Chinese } & \multirow{2}{*}{ T-value } & S.p \\
\cline { 2 - 5 } & Mean & S.d & Mean & S.d & & \\
\hline $\begin{array}{c}\text { Near Miss } \\
\text { (during } 1 \\
\text { month) }\end{array}$ & 3.70 & 2.506 & 7.88 & 3.812 & 7.578 & .000 \\
$\begin{array}{c}\text { Actual } \\
\text { experience } \\
\text { disaster }\end{array}$ & 3.57 & 2.356 & 6.59 & 3.694 & 7.164 & .000 \\
\hline
\end{tabular}

In addition, to understand the relationship between safety awareness of construction workers and industrial disasters, the construction workers' experience of any industrial disaster was researched (See Table 4). In terms of near misses, Korean workers experienced an average of 3.70 near misses while Chinese workers experienced 7.88, which was a statistically significant difference ( $p<.001)$. Moreover, in terms of industrial disasters, Korean workers experienced 3.57 while Chinese workers experienced 6.57, which was again statistically significant $(p<.001)$. From these results, it was found that Chinese workers are usually exposed to more near misses and industrial disasters.

\subsection{Correlation analysis between safety awareness and disaster experience}

Through the comparison of safety awareness and industrial disasters, Chinese construction workers had lower safety awareness and more experience of industrial disasters compared to Korean construction workers. Therefore, to understand the relation between safety awareness and industrial disasters, a correlation analysis was conducted.

As shown in Table 5 of the correlation 
Table 5. Correlation analysis of variables to Chinese construction worker

\begin{tabular}{|c|c|c|c|c|c|c|c|c|c|c|}
\hline No & Variables & 1 & 2 & 3 & 4 & 5 & 6 & 7 & 8 & 9 \\
\hline 1 & experience disaster & 1 & & & & & & & & \\
\hline 2 & Risk-Processing system & $-.473(\star \star)$ & 1 & & & & & & & \\
\hline 3 & $\begin{array}{c}\text { Safety education } \\
\text { efficiency }\end{array}$ & $-.536(\star \star)$ & $.587(\star \star)$ & 1 & & & & & & \\
\hline 4 & Safety Intelligibility & $-.553(\star \star)$ & $.545(\star \star)$ & $.521(\star \star)$ & 1 & & & & & \\
\hline 5 & Safety rules observance & $-.697(\star \star)$ & $.645(\star \star)$ & $.627(\star \star)$ & $.728(\star \star)$ & 1 & & & & \\
\hline 6 & Age & $.437(\star \star)$ & -.177 & -.093 & $-.410(\star \star)$ & $-.380(\star \star)$ & 1 & & & \\
\hline 7 & Academic career & $-.527(\star \star)$ & $.363(\star \star)$ & $.477(\star \star)$ & $.365(\star \star)$ & $.425(\star \star)$ & -.167 & 1 & & \\
\hline 8 & Job career & -.162 & .182 & .196 & .106 & .148 & $.572(\star \star)$ & .139 & 1 & \\
\hline 9 & Working hours & -.006 & -.058 & -.027 & $-.204(*)$ & -.196 & .169 & -.025 & .003 & 1 \\
\hline
\end{tabular}

* Correlation is significant at the 0.05 level (2-tailed).

$\star \star$ Correlation is significant at the 0.01 level (2-tailed).

Table 6. Correlation analysis of variables to Korean construction workers

\begin{tabular}{|c|c|c|c|c|c|c|c|c|c|c|}
\hline No & Variables & 1 & 2 & 3 & 4 & 5 & 6 & 7 & 8 & 9 \\
\hline 1 & experience disaster & 1 & & & & & & & & \\
\hline 2 & Risk-Processing system & $-.265(\star \star)$ & 1 & & & & & & & \\
\hline 3 & $\begin{array}{l}\text { Safety education } \\
\text { efficiency }\end{array}$ & -.135 & $.460(\star \star)$ & 1 & & & & & & \\
\hline 4 & Safety Intelligibility & -.084 & $.382(\star \star)$ & $.374(\star \star)$ & 1 & & & & & \\
\hline 5 & Safety rules observance & $-.281(* *)$ & $.417(\star \star)$ & $.368(\star \star)$ & $.440(\star \star)$ & 1 & & & & \\
\hline 6 & Age & .135 & -.022 & -.117 & -.025 & -.184 & 1 & & & \\
\hline 7 & Academic career & -.064 & .021 & -.009 & -.037 & .077 & $-.239(\star)$ & 1 & & \\
\hline 8 & Job career & .012 & -.046 & -.049 & -.013 & .101 & $.302(\star \star)$ & -.053 & 1 & \\
\hline 9 & Working hours & .027 & -.085 & .088 & -.137 & .013 & .038 & -.167 & .012 & 1 \\
\hline
\end{tabular}

* Correlation is significant at the 0.05 level (2-tailed).

** Correlation is significant at the 0.01 level (2-tailed).

analysis result, all four detailed questions related with safety awareness had a significant correlation with disaster experience among Chinese construction workers. In particular, the correlation between safety rules observation and disaster experience was shown as the highest $(\mathrm{r}=-$ 0.697), followed by safety intelligibility ( $\mathrm{r}=$ $0.553)$, safety training efficiency $(\mathrm{r}=-0.536)$, and risk-processing system, in that order.

However, as shown in Table 6 of the correlation analysis result, four detailed questions related with safety awareness did not have that significant a correlation with disaster experience among Korean construction workers. The correlation between safety rules observation and disaster experience was high $(r=-0.281)$, followed by risk-processing $\operatorname{system}(\mathrm{r}=-0.265)$.

For Korean construction workers, there was little correlation between individual personality and safety awareness and disaster experience.

On the other hand, for Chinese construction workers, there were high correlations between age and educational background and safety awareness and disaster experience. In particular, age $(r=0.437)$ showed a static correlation with disaster experience, and educational background $(\mathrm{r}=-\mathrm{527})$ showed a negative correlation. That is, Chinese construction workers who were old and had low educational background had more experience of industrial disasters.

In addition, for Chinese construction workers, there was a correlation between age and 
educational background and safety awareness. The younger the age, the higher the safety intelligibility and safety rules observation. Moreover, the higher the educational background, the higher safety awareness in all of the four detailed factors. That is, Chinese construction workers who were younger and had a higher educational background had high safety awareness.

\subsection{Safety management improvement plan when entering the construction market in China}

Based on the comparative analysis of the safety awareness of Korean and Chinese construction workers, a plan to improve safety management was made for companies seeking to make inroads into the construction market in China.

To improve the observation of safety rules, construction workers should be made to strictly observe the laws and regulations, and the site safety manager should periodically inspect safety equipment and gear at the construction site, and have a system to check the state of construction safety management in real time. In addition, it should be systemized that the person in charge of construction disaster (manager, worker) should take legal responsibility, not to mention be subject to economic or personnel sanctions.

In terms of safety training and risk-processing system, safety training should be provided to new, mid-career and older workers to explain the potential dangers and risk-processing system in detail. In particular, mid-career and older workers usually have a low educational background, and are likely to have a low understanding of safety training. For this reason, easier safety training should be developed in order for Chinese construction workers to have an interest in safety.

\section{Conclusion}

From the comparison of construction workers 'safety awareness between China and South Korea, Korean workers were shown to have higher safety awareness than Chinese construction workers. In addition, due to the difference in safety awareness, Chinese workers experienced more industrial disasters than Korean workers. When it comes to safety awareness and experience of industrial disasters, the safety awareness of Chinese construction workers should be improved to prevent industrial disasters for construction workers in China. In particular, Chinese construction workers do not have as stronger safety awareness as Korean construction workers, and this has the closest relation to the frequent experience of construction incidents of Chinese workers. Thus, when Korean companies enter the construction market in China, they should strictly apply safety rules to Chinese construction workers to change their safety awareness.

In addition, some of the Chinese construction workers who are old and have a low educational background had low safety awareness and experienced more safety incidents. Therefore, Korean companies that intend to make inroads into China should make strong efforts to improve the safety awareness of the construction workers who are old and have a low educational background. Based on the research findings, a plan to improve safety management is presented for Korean companies that intend to enter China.

These research findings are expected to provide useful data to improve safety awareness and resolve insensitivities to the safety of Chinese construction workers and managers when Korean construction companies make inroads into the construction market in China. 


\section{Acknowledgement}

This research was supported by the Daegu University Research Grant, 2011.

\section{References}

1. National Bureau of Statistics of China. [2001-2009 National construction production analysis report]. Beijing (China): National Bureau of Statistics of China; 2010. p. 1-3. Chinese.

2. Ministry of Construction. [2009 National construction safety situation analysis report]. Beijing (China): Ministry of Construction. 2010. p. 1-2. Chinese

3. Lee CJ. A study on the safety consciousness and improvement policy in construction works field [master's thesis]. Gwangju (Korea): Chosun University; 2007. 70 p.

4. Lee YS. Research about the effect of the construction worker's safety awareness on the disaster and its countermeasure [master's thesis]. Seoul (Korea): Dongguk University; 1994. p. 42-3

5. Lee JY. A study on the safety consciousness of the laborer in the construction job site [master's thesis]. Suwon (Korea): Suwon University; 1995. p. 72-4.

6. Kim DH, Ko BI, Lim HK. Effective safety education schemes at construction sites for enhancing safety consciousness of workers and engineers. Journal of Korean Institute of Industrial Safety. 1999 Jun;14(2):163-9.

7. Lee SH. A study on the concept of safety by workers at the construction site [master's thesis]. Chungju (Korea): Chungju University; 2000, p. 63-4.

8. Jeon JM. A study on the industry safety awareness of construction workers [master's thesis]. Gyeongsan (Korea): Yeungnam University; 2002. p. 41-2.

9. Kim YJ. Safety consciousness for construction disaster of construction workers -Focused on the construction workers in Gyeonggi province- [master's thesis]. Seoul (Korea): Hanyang University; 2005. p. 45-6.

10. Cho JW. A study on causal effects of safety training and safety awareness of construction industry workers affecting industrial incidents [dissertation]. Seoul (Korea): Dongguk University; 2009. 116 p.

11. Lee HC, Yeo SK, Go SS. A study on the improving safety management by analyzing safety consciousness of construction labors. Journal of the Korea Institute of Building Construction. 2009 Jun;9(3):51-8.
12. Kim JT. The study for factors influencing construction worker's safety consciousness [master's thesis]. Seoul (Korea): Soongsil University; 2009. p. 56-7.

13. Oh JY. Study on the method of raising safety awareness for prevention of construction accident [master's thesis]. Seoul (Korea): Kyunghee University; 1994. 98 p.

14. Kang BS, Kim GS. The statistical analysis of social science. Hannarae. 1998. 608 p. 